\title{
Spatio-temporal Evolution Characteristics and Influencing Factors of Carbon Emission Reduction Potential in China
}

\section{Zhangwen Li ( $\sim$ lzw1226x@gmail.com )}

South China University of Technology https://orcid.org/0000-0002-4770-502X

\section{Caijiang Zhang}

South China University of Technology https://orcid.org/0000-0002-1373-8296

\section{Yu Zhou}

South China University of Technology

\section{Research Article}

Keywords: Carbon emission reduction potential, Carbon abatement cost, Directional Distance Function, Policymaker preference, Spatio-temporal evolution, Spatial Durbin model

Posted Date: May 4th, 2021

DOI: https://doi.org/10.21203/rs.3.rs-436557/v1

License: (c) (i) This work is licensed under a Creative Commons Attribution 4.0 International License. Read Full License 


\title{
2 Spatio-temporal evolution characteristics and influencing 3 factors of carbon emission reduction potential in China
}

\author{
Zhangwen Li ${ }^{1}$, Caijiang Zhang ${ }^{1, *}$, Yu Zhou ${ }^{1}$ \\ School of Economics and Finance, South China University of Technology, Guangzhou 510006, China; \\ Correspondence: zcj@scut.edu.cn (Caijiang Zhang)
}

\begin{abstract}
This study first attempts to use the parameterized quadratic Directional Distance Function (DDF) approach to calculate China's provincial carbon abatement cost and carbon reduction potential (CRP) under different scenarios from 2000 to 2017. Afterward, considering three different scenarios, we analyze the Spatio-temporal characteristics and the dynamic evolution pattern of CRP. We also conduct the spatial autocorrelation test and spatial Durbin model to analyze the spatial spillover effects and influencing factors of CRP. The results are obtained as follows: CRP across the three scenarios varies considerably across provinces and different-located groups. CRP higher areas are mainly located in the economically developed eastern coastal regions, while most provinces with low CRP are concentrated in the western region. The spatial autocorrelation test indicated that provinces with a similar CRP showed a significant geographic agglomeration, and the agglomeration effect was strengthened first and then weakened. Simultaneously, the local spatial distribution of MCRP, FCRP, and ECRP shows a slight spatial polarization feature. Finally, through the SDM analysis and spillover effect decomposition, we find that improvement of regional CRP not only depends on economic development, industrial structure adjustment, and energy efficiency elevation, but also involves energy structure optimization, low-carbon innovation, and population. The low-carbon innovation provides critical support for local CRP under the efficiency scenario but restrains the local CRP under the fairness scenario. Therefore, the central government should emphasize local conditions and the ex-ante scenario assessment, strengthen regional interactive governance, optimize energy efficiency, and promote the application of clean energy to enhance CRP.
\end{abstract}

Keywords Carbon emission reduction potential; Carbon abatement cost; Directional Distance Function; Policymaker preference; Spatio-temporal evolution; Spatial Durbin model

\section{Introduction}

Economic development has always been closely related to natural resource consumption (Song et al. 2019). Extensive resource utilization has brought about serious ecological damage and environmental consequences. Over the past 40 years, China has experienced rapid economic growth and the speedy growth of energy demand, but the contradiction between resource environmental constraints and economic development has become increasingly prominent (Wei et al. 2020; Zhang et al. 2020). Faced with the severe challenge of environmental sustainability, the Chinese government has taken many measures to promote green low-carbon development. For example, China has pledged to reduce $\mathrm{CO}_{2}$ emissions per unit GDP by 60\%-65\% in 2030 compared with 2005 levels at the 2015 Paris climate conference (Chen et al. 2019). Furthermore, the government reiterated that China would increase its nationally determined contribution, strive to reach the carbon peak by 2030, and achieve "carbon neutrality" by 2060 at the 75th UN General Assembly. Innovation-driven and green, zero-carbon-oriented industrial changes have become the vane of China's modern economic system. However, China has a vast territory and significant Interregional economic differences, which will inevitably lead to differences in the spatial distribution of carbon reduction potential (CRP) in the process of green low-carbon development. Therefore, to provide a theoretical basis for achieving high-efficiency carbon emission reduction in China, it is imperative to accurately grasp the evolutionary characteristics of CRP and its driving factors.

In fact, exploiting regional carbon emission reduction potential and exploring new green low-carbon development paths are common concerns worldwide. A low CRP would construct a significant barrier to environmental sustainability in developed and developing countries. With the improvement of status in the world economy and fossil energy field (Wei et al. 2020), China's CRP Spatio-temporal evolution characteristics and influencing factors are a vital epitome for other developing countries. 
This paper attempts to use the parameterized quadratic function of the Directional Distance Function (DDF) approach to estimate the carbon abatement costs and evaluate the provincial CRP through setting three different scenarios. This paper contributes to current literature in 3ways. First, this study innovatively evaluates the provincial CRP from the perspective of policymakers' preferences. Few studies have examined the carbon emission reduction potential in China from the perspective of policymakers' preferences against this background up to now. Moreover, differing from the existing literature about the carbon emission reduction potential (Wei et al. 2012; An et al. 2018), the purpose of this paper is to analyze each province's CRP and determine how to make regional environmental policies aimed at motivating carbon emission reduction potential, rather than how to allocate $\mathrm{CO}_{2}$ abatement responsibility among provinces or how much $\mathrm{CO}_{2}$ should be reduced. Second, we analyze the spatial-temporal evolution characteristics and the dynamic evolution pattern of CRP and clarify the heterogeneous characteristics of CRP under three different scenarios. Third, we employ the spatial econometric model to investigate the CRP's influencing factors in China, while spatial econometric models are rarely used to study the influencing factors of CRP. Owing to CRPs have significant spatial dependence and econometric models without considering the spatial dependence of variables often lead to inaccurate results. Therefore, our research evaluates the changes in Chinese provinces' CRP and the effects of related factors on CRP more accurately since 2000 , which can provide more reference for policymakers to stimulate the potential of regional low-carbon transformation.

The rest of the paper is structured as follows. "Literature review" section presents the related literature. "Methodology and data" section describes the CRP measurement approach, the DDF, spatial economic models, variables selection, and data sources. "Spatio-temporal evolution characteristics of carbon reduction potential" presents the Spatio-temporal characteristics and the dynamic evolution pattern of CRP under different scenarios. The empirical results are reported in the "Empirical results" section. "Conclusions and policy implications" section summarizes and provides the corresponding policy implications.

\section{Literature review}

Since scholars have gradually realized the importance of resources and the environment for human survival and sustainable economic development, they have incorporated the environment as an essential factor into the economic research framework. In the subsequent research, many early studies mainly investigated energy-related carbon emissions and its influencing factors (Geng et al. 2013; Zhang and Da 2015), the law of Spatio-temporal evolution (Shi et al. 2014; Ding et al. 2019) and driving mechanism (Tian et al. 2013; Jiang et al. 2017). In recent years, an increasing number of studies have discussed the carbon emission reduction cost and reduction potential worldwide (Criqui et al. 1999; Guo et al. 2011; Chen and Xiang 2019).

This section reviews the existing literature on the carbon emission reduction potential from the three aspects: measurement of the abatement cost, the concept of the carbon emission reduction potential, and evaluation of the carbon emission reduction potential.

\section{Research on carbon abatement cost measurement}

Shadow prices provide a critical way to estimate the marginal abatement cost of undesirable outputs (Zhou et al. 2014). In literature related to the marginal abatement costs, most existing studies generally focused on estimating shadow prices at the regional/sectors level (Lee 2011; Molinos-Senante et al. 2015; Wang et al. 2017; Chen and Xiang 2019). In previous studies, various methods were employed to estimate the shadow price of pollutants. Färe et al. (1993) first derived the shadow price of undesirable outputs based on the Shephard output distance function. Lee et al. (2002) estimated the shadow prices of sulfur oxides (SOx), nitrogen oxides (NOx), and total suspended particulates (TSP) by formulating the nonparametric production model specific to the directional distance function for the case of a single good output and pollutant. Ke et al. (2008) used the Linear Programming (LP) approach to compute the shadow prices of SO2 emissions in China during the 1996-2003 period, found that the shadow price in the west region is the highest. 
The estimation of the carbon shadow price shares the same shadowing pricing procedure as other greenhouse gases, which shifted scholars' attention to estimating carbon shadow price Zhou et al. (2014). As for literature concerning the carbon abatement cost measurement, there are, for instance, Choi et al. (2012) employed the dual model of the slacksbased Data Envelopment Analysis (DEA) model to estimate the abatement costs of $\mathrm{CO}_{2}$ emissions. Wang et al. (2011) estimated the marginal $\mathrm{CO}_{2}$ abatement costs in China with the framework of the nonparametric method. Nevertheless, the nonparametric DEA technique is not well-suited to derive the shadow prices due to its non-differentiability (Färe et al. 2005). By contrast, the DDF is thought to provide a more flexible method to evaluate the $\mathrm{CO}_{2}$ marginal abatement costs. The related studies include Tang et al. (2016) and Ji and Zhou (2020), among others. Furthermore, the quadratic DDF model might be more suitable for a sample that faces mandatory $\mathrm{CO}_{2}$ emissions reduction or prefer to conduct voluntary $\mathrm{CO}_{2}$ emissions reduction (Zhou et al. 2015). Therefore, the quadratic DDF model has been widely employed to evaluate carbon abatement costs in recent years.

\section{Research on carbon emission reduction potential}

The CRP has different connotations. The existing studies on defining the carbon dioxide reduction potential from different perspectives can be mainly classified into three categories according to their results. The first strand of literature mainly focuses on the differences in emission reduction of different electricity structures vehicles in the transportation sector. For example, Ketelaer et al. (2014) explored the $\mathrm{CO}_{2}$ mitigation potential of German commercial transport based on the difference of $\mathrm{CO}_{2}$ emissions from conventional to electric light commercial vehicles. Zhang et al. (2019) used the backward analysis to calculate the proportion limit of coal power consumption by urban rail transit, and then analyze the emission reduction potential of rail transit under different combinations of electricity consumption structures.

The second strand of literature defines the gap between the $\mathrm{CO}_{2}$ emissions for the base year and the estimated year under different scenarios as the $\mathrm{CO}_{2}$ emissions reduction potentials of various sectors. For instance, Lin and Xie (2014) calculated the carbon mitigation potential in China's transport industry under moderate and advanced emission-reduction scenarios. Lin and Ouyang (2014) investigate the reduction potential of $\mathrm{CO}_{2}$ emissions in the Chinese non-metallic mineral products industry by setting three scenarios. An et al. (2018) relies on four scenario analyses with the aim to estimate the potential of $\mathrm{CO}_{2}$ emission reduction in the iron and steel industry in China.

The third strand of literature defines the inefficiency level or excesses of carbon dioxide emissions as the $\mathrm{CO}_{2}$ emissions reduction potentials. For example, Choi et al. (2012) employed the non-radial slacks-based measure(SBM) framework to measure the excesses of undesirable output, and they defined the room for improvement in carbon emissions as the $\mathrm{CO}_{2}$ emissions reduction. Wei et al. (2012) established that the abatement potential of $\mathrm{CO}_{2}$ reflects the inefficiency level of carbon dioxide emission during the production process, the study expected that the richer provinces are normally accompanied by lower $\mathrm{CO}_{2}$ abatement potential.

Several scholars have devoted to evaluate the carbon emission reduction potential in China by using the nonparametric DEA approach. For example, using the DEA model, Guo et al. (2011) evaluated the carbon emission reduction potential in Chinese provinces, revealing that energy conservation technology promotion and inter-regional technical cooperation can reduce carbon emissions in technically inefficient regions. Further, various extensions of the basic DEA models have been proposed for estimation. Bian et al. (2013) took non-fossil energy as a fixed input and proposed a non-radial DEA approach combining energy structure adjustment and DEA-based target setting together to measure potential $\mathrm{CO}_{2}$ emission reductions. Choi et al. (2012) employed the SBM of the non-radial DEA model to develop the potential $\mathrm{CO}_{2}$ emissions reduction (PCR) index. In addition, one special case is Wei et al. (2012), who take both equity and efficiency principles into account in evaluating $\mathrm{CO}_{2}$ abatement capacity. However, it is different from our research. Specifically, we estimate CRP depends on the policymakers' preferences to analyze each province's CRP, rather than how to allocate $\mathrm{CO}_{2}$ abatement among regions or how much $\mathrm{CO}_{2}$ should be reduced.

As discussed above, scholars have conducted extensive studies on the concept and evaluation of CRP and found that many regions/sectors have the potential to reduce carbon emissions (Akimoto et al. 2010; Zhu et al. 2020), but still need 
further exploration. First, existing literature mainly focuses on the excesses of carbon emissions, rather than a comprehensive evaluation system include policymakers' preferences, which may lead to an incomplete understanding of the regional CRP. Thus, it must be further explored with additional dimensions and based on the policymakers' preferences. Second, there is a lack of discussion on the spatial-temporal characteristics of CRP and its influencing factors. Finally, scholars mainly focus on the difference between the $\mathrm{CO}_{2}$ emissions for the base year and the estimated year, but ignore the spatial factors.

Therefore, this paper attempts to provide a comprehensive evaluation of the CRP in 30 Chinese provinces by setting three different scenarios based on Wei et al. (2012) and clarify its determinants. This study also analyzes the Spatiotemporal evolution characteristics of CRP under three scenarios. Then, we use the Moran'I index to test whether there is spatial autocorrelation of CRP in various provinces. Lastly, based on the theoretical basis of the STIRPAT model, this study constructs the spatial econometric model of regional development factors to investigate the effects of each factor on CRP and estimates the spatially divergent features, with the purpose of providing theoretical support for making policy of promoting regional carbon reduction.

\section{Methodology and data}

\section{Measuring the carbon reduction potential}

This paper uses a two-step approach to estimate the CRP under three scenarios from 2000 to 2017 in the study. First, we apply the parameterized quadratic function of the DDF method to estimate the carbon shadow price in 30 Chinese provinces from 2000 to 2016. Second, considering three different scenarios differentiated by different policy preferences, we evaluate CRPs (MCRP, FCRP, and ECRP) since 2000. Following the idea of Wei et al. (2012), the calculation of the CRP index is shown in formula (1):

$$
C R P=w \times \text { Equity }_{i t}+(1-w) \times \text { Efficiency }_{i t}
$$

Where $w$ is weight reflects the policymakers' preferences, Equity $y_{i t}$ and Efficiency ${ }_{i t}$ are the index of the development equity and carbon abatement efficiency of province $i$ in year $t$, respectively. In terms of the development equity index, per capita regional carbon emissions and per capita GDP indicators are both highly recognized fair distribution indicators (den Elzen and Lucas 2005; Pan et al. 2017), in which the former can reflect the equal development rights of the region, and the latter can reflect the ability of the region to pay. In terms of the carbon abatement efficiency index, this paper selected carbon emission intensity and carbon abatement cost to reflect the overall efficiency of carbon emission reduction, in which carbon emission intensity is often used to reflect carbon emission efficiency (Sun, 2005; Zhang and Wei, 2015), and the carbon marginal abatement cost reflect the difficulty level of pollutant reductions (Färe et al. 2006). Areas with high carbon emission intensity and low marginal emission reduction costs can be identified as key pollution reduction areas in practice. All variables are normalized by the "Min-Max" method. ${ }^{1}$

\section{Scenarios analysis assumption}

The CRP is a kind of objective reflection related to regional economic development and resource endowments, as well as policymakers' own subjective constraints, as the policymakers' tolerance of regional inequity in carbon emissions impacts carbon emission reduction pressure (Chen et al. 2016). Most existing literature has constructed a comprehensive indicator system encompassing capability, equity, and responsibility (Qin et al. 2017; Dong et al. 2018; Ma et al. 2020), which results in a new research angle that includes both fairness and efficiency simultaneously. Thus, this paper conducts the evaluation of provincial CRP via three scenarios differentiated by policy preferences. In line with Wei et al. (2012), we set three scenarios as follows: (i) Moderation scenario, of which fairness and efficiency of carbon emission reduction responsibilities are equally important. A moderation scenario reflects the possible situation; however, the purpose of a

\footnotetext{
${ }^{1}$ The "Min-Max" normalization method converts $z_{i}$ to $s_{i}$ by $S_{i}=\left(z_{i}-\min z\right) /(\max z-\min z)$. The variable of the carbon shadow price is reverse transformed
} 
moderation scenario is not to provide precise estimates of the regional reduction potential conditions but to clarify the significant factors that contribute to regional carbon emissions reduction in the future. Besides, it is the benchmark for setting the other two scenarios. (ii) Fairness scenario, of which policymakers more focus on the fairness of allocating responsibilities for carbon reduction. (iii) Efficiency scenario, of which policymakers pay more attention to carbon reduction efficiency, the province has a higher (lower) capacity to undertake more (less) reduction burden. The main advantage of the scenario analysis is that we can have a relatively accurate examination and comprehensive analysis on the Spatio-temporal distribution of CRP. These features could yield valuable information to policymakers, helping them design better regional environmental policies compatible with low-carbon development.

\section{Measuring the carbon shadow price}

The DDF, developed initially by Shephard (1970) and applied by Färe et al. (1993) in empirical fields, has gained tremendous popularity in measuring the abatement cost of pollutants owing to its flexibility. The distance function does not require any assumptions concerning cost minimization or revenue maximization and information on input or output prices. The DDF method allows researchers to simultaneously expand desirable outputs and reduce undesirable outputs based on a given direction vector (Chung et al. 1997). Thus, this paper uses the parameterized quadratic function of the DDF to estimate the carbon shadow price before calculating the $\mathrm{CO}_{2}$ abatement efficiency index. Following the idea of Chung et al. (1997) and Färe et al. (2005), the directional output distance function can be defined as follow :

$$
\stackrel{\mathbf{u}}{D}\left(x, y, b ; g_{y},-g_{b}\right)=\max \left\{\beta:\left(y+\beta g_{y}, b-\beta g_{b}\right) \in F(x)\right\}
$$

Where $\left(g_{y},-g_{b}\right)$ is the direction vector that indicates the direction by which the output combination are scaled. Moreover, we assume that a joint-production process in which each observation uses a nonnegative vector of inputs denoted as $x$ to produce a nonnegative vector of desirable outputs denoted as $y$ and a nonnegative vector of undesirable outputs denoted as $b$. Then, production technology can be represented by the output possibility set $F(x)=\{(y$, $b): x$ can produce $y$, and $b$ \} describes the set of feasible input-output vectors.

In line with Chung et al. (1997), this paper chooses $\mathrm{g}=(1,-1)$ as the direction vector to simplify the parameter estimation and satisfies the translation property of the DDF. In addition, we assume that there are $i=1, \ldots, 30$ provinces in $t=1, \ldots, T$ years, three inputs (capital, energy consumption, and labor), one desirable output (GDP), and one undesirable output (carbon emissions). The parametric quadratic directional output distance function form can be shown as follow:

$$
\begin{aligned}
\stackrel{\mathrm{ur}}{D}\left(x_{i}^{t}, y_{i}^{t}, b_{i}^{t} ; g_{y},-g_{b}\right) & =\alpha_{0}+\sum_{n=1}^{3} \alpha_{n} x_{i}^{t}+\beta_{1} y_{i}^{t}+\gamma_{1} b_{i}^{t}+\frac{1}{2} \sum_{n=1}^{3} \sum_{n=1}^{3} \alpha_{n n} x_{n i}^{t} x_{n i}^{t}+\sum_{n=1}^{3} \delta_{n} x_{n i}^{t} y_{i}^{t} \\
& +\sum_{n=1}^{3} v_{n} x_{n i}^{t} b_{i}^{t}+\frac{1}{2} \beta_{2}\left(y_{i}^{t}\right)^{2}+\frac{1}{2} \gamma_{2}\left(b_{i}^{t}\right)^{2}+\mu y_{i}^{t} b_{i}^{t}
\end{aligned}
$$

Following Aigner and Chu (1968), this study uses a deterministic linear programming model to estimate the parameters $\left(\alpha_{0}, \alpha_{n}, \alpha_{n i}, \delta_{n}, v_{n}, \beta_{2}, \gamma_{2}, \mu\right)$. The constraint conditions cover the feasibility, monotonicity, linear homogeneity or translation property of distance function, which takes the following Eq. (4).

$$
\begin{aligned}
& \min \sum_{t=1}^{T} \sum_{i=1}^{30} D^{t}\left(x_{i}^{t}, y_{i}^{t}, b_{i}^{t} ; 1,-1\right) \\
& \text { s.t. } \\
& \text { uur } \\
& \text { i) } \partial D^{t}\left(x_{i}^{t}, y_{i}^{t}, b_{i}^{t} ; 1,-1\right) / \partial b \geq 0, i=1, \ldots, 30, t=1, \ldots, T \\
& \text { uur } \\
& \text { ii) } \partial D^{t}\left(x_{i}^{t}, y_{i}^{t}, b_{i}^{t} ; 1,-1\right) / \partial y \leq 0, i=1, \ldots, 30, t=1, \ldots, T \\
& \text { uur } \\
& \text { iii) } \partial D^{t}\left(x_{i}^{t}, y_{i}^{t}, b_{i}^{t} ; 1,-1\right) / \partial x_{n} \leq 0, i=1, \ldots, 30, t=1, \ldots, T \\
& \text { iv) } \hat{\beta}_{1}-\hat{\gamma}_{1}=-1, \hat{\beta}_{2}=\hat{\gamma}_{2}=\hat{\mu}, \hat{\delta}_{n}=\hat{v}_{n} \\
& \text { v) } \alpha_{n^{\prime} n}=\alpha_{n n^{\prime}}, n, n^{\prime}=1,2,3
\end{aligned}
$$

Once the parameters are estimated, we can apply Shepard derivation to derive the relationship between the undesirable output price $q$ and the desirable output $p$, see Eq.(5). 


$$
\begin{aligned}
\frac{q}{p} & =-\frac{\partial \stackrel{\mathbf{u}}{D}\left(x, y, b ; g_{y}, g_{b}\right) / \partial b}{\partial D\left(x, y, b ; g_{y}, g_{b}\right) / \partial y} \\
& =-\frac{\gamma_{1}+\gamma_{2} b+\sum_{n=1}^{3} v_{n} x_{n}+\mu y}{\beta_{1}+\beta_{2} b+\sum_{n=1}^{3} \delta_{n} x_{n}+\mu b}
\end{aligned}
$$

\section{Measuring the carbon emission}

Carbon emissions of Chinese provinces need to be calculated before calculating the $\mathrm{CO}_{2}$ abatement efficiency index. According to the IPCC Guidelines for National the reduction potential of pollutants Inventories (IPCC 2006), the total fuel-based carbon emissions are estimated according to the following formula (6). ${ }^{2}$

$$
C E_{i}=\sum_{m=1}^{17} E C_{i m} \times N C V_{i m} \times C C_{i m} \times O_{i m} \times \frac{44}{12}
$$

where $C E_{i}$ denotes energy-related carbon emissions by fossil fuel's category $m$ in province $i, E C_{i m}$ is the consumption of fossil fuels $m, N C V_{i m}, C C_{i m}$ and $O_{i m}$ are respectively denote net calorific value ${ }^{3}$, carbon content, and oxygenation efficiency (Liu et al. 2015).

\section{Measuring the dynamic evolution characteristic}

Kernel density estimation (KDE) is an essential nonparametric estimation method used for point data density visualization, which can describe the actual data distribution based on the data's intrinsic attributes without needing any prior information. Therefore, this paper employs KDE to analyze the dynamic evolution of CRP in China. The KDE can be defined as:

$$
\hat{f}=(1 / n h) \sum_{i=1}^{n} K\left(\left(r-R_{i}\right) / h\right)
$$

Where $\hat{f}$ denotes the kernel density value, $h$ denotes the bandwidth of $\mathrm{KDE}, K(g)$ represents the Gaussian kernel function, which is expressed in Eq.(8), $g$ represents the estimating site, $R_{i}$ represents the number $i$ sample site.

$$
K(g)=(1 / \sqrt{2 \pi}) \operatorname{gexp}\left(-g^{2} / 2\right)
$$

\section{Spatial econometric model}

\section{Spatial autocorrelation model at the global level}

To test whether there is a spatial autocorrection in provincial CRP, we adopt the global Moran's I index to examines the spatial correction of CRP in Chinese 30 provinces. The spatial autocorrelation index is calculated by Eqs. (9) to (11):

$$
\begin{aligned}
& I=\frac{\sum_{i=1}^{n} \sum_{j \neq i}^{n} W_{i j}\left(Y_{i}-\bar{Y}\right)\left(Y_{j}-\bar{Y}\right)}{S^{2} \sum_{i=1}^{n} \sum_{j=1}^{n} W_{i j}} \\
& S^{2}=\frac{1}{n} \sum_{i=1}^{n}\left(Y_{i}-\bar{Y}\right)^{2} \\
& \bar{Y}=\frac{1}{n} \sum_{i=1}^{j} Y
\end{aligned}
$$

\footnotetext{
${ }^{2}$ Different from considering 7 energy types, it is found that the measurement accuracy is significantly improved after supplementing ten types of energy consumption data by constructing the accuracy improvement rate index, the results are presented as Supplementary material.

${ }^{3}$ Liu Z (2015) pointed out that the carbon emission factor in the IPCC report is approximately higher than the value in China's "United Nations Framework Convention on Climate Change (UNFCCC)" report. Therefore, we use the net calorific value provided in the China Energy Statistical Yearbook, which is more suitable for China's national conditions.
} 
Where $I$ represents the index of global spatial autocorrelation; $Y_{i}$ and $Y_{j}$ represent the values of CRP in province $i$ and $j ; n$ represents the total number of provinces; $W_{i j}$ represents the spatial weight matrix, this paper sets 30 provinces with neighbors that could be adjacent, $W_{i j}=1$ if two provinces are neighbors; otherwise, $W_{i j}=0$. The value range of Moran's $I$ is $[-1,1], I<0$ indicates that there is a negative spatial autocorrelation, $I>0$ indicates that there is a positive spatial autocorrelation.

\section{Spatial autocorrelation model at the local scale}

This paper uses the Local spatial autocorrelation proposed by Anselin (1995) to explore the statistically significant spatial clusters and dispersion of the provincial CRP. The Local Moran's I index can be calculated using Eq. (12):

$$
I_{i}=\frac{Y_{i}-\bar{Y}}{S^{2}} \sum_{j=1}^{n} W_{j \neq i}\left(Y_{j}-\bar{Y}\right)
$$

Where $I_{i}$ represents the Local Moran's $I$, and the other symbols represent the same as in Eqs. (9) to (11). when $I_{i}$ is significantly positive, there exists High-High (H-H) or Low-Low (L-L) agglomeration, indicating that the province and its adjacent provinces have a high or low degree of CRP agglomeration. when $I_{i}$ is significantly negative, there exists High-Low (H-L) or Low- High (L-H) agglomeration.

\section{Spatial panel model}

The spatial panel model predominantly including the spatial lag model (SLM), spatial error model (SEM), and spatial Durbin model (SDM). As a general form of SLM and SEM, SDM considers the spatial correlation of dependent variables and independent variables simultaneously. SLM mainly explores whether the independent variables in a region are affected by the dependent and independent variables in adjacent regions. Therefore, this study chooses SDM to examine the geographical space feature of CRP under moderation, fairness, efficiency scenarios. The model is constructed as follows:

$$
C R P_{i t}=\alpha+\rho \sum_{j=1}^{n} W_{i j} C R P_{t}+\beta X_{i t}+\theta \sum_{j=1}^{n} W_{i j} X_{i t}+\varepsilon_{i t}
$$

Where $X_{i t}$ represents the independent variables; $W_{i j}$ is the spatial weight matrix; $\rho$ is the spatial lag autoregressive coefficient; $\beta$ is the estimated coefficient of the independent variable; $\theta$ represents the coefficient of the space-lag term of the independent variable, and $\varepsilon_{i t}$ is a random perturbation term.

\section{Variables and data}

\section{Variable selection in measuring carbon reduction potential}

In terms of the variables in measuring carbon shadow price, input indicators are capital, labor force, and energy consumption. Besides, the actual GDP was adopted as a desirable output indicator, and carbon emissions were determined as an undesirable output indicator (see Table 1). In terms of the variables in measuring the CRP, we select per capita regional carbon emissions and per capita GDP to construct the development equity index. Besides, we select carbon emission intensity and carbon shadow price to construct the carbon abatement efficiency index (see Table 2).

\section{Influencing factors of carbon reduction potential}

Many factors influence CRP. Existing studies combined with the STIRPAT model show that population, economic development, industrial structure, research and development (Dietz and Rosa 1994; Cheng et al. 2020), energy structure (Yu et al. 2018), energy efficiency are the main factors influencing carbon emission. On the basis of the work of Shahbaz et al. (2016), the increase in domestic openness will attract more foreign investments and high energy demand for production (Wang and Zheng 2020), so we also consider openness and employ the ratio of total import and export to GDP to represent it, in which the total import and export volume are converted into RMB. Thus, we select population size, economic development, industrial structure, low-carbon innovation, energy structure, energy efficiency, economic opening rate as explanatory variables to analyze the influencing factors of CRP (see Table 3).

It is worth noting that low-carbon innovation plays a vital role in the process of carbon reduction (Zhang et al. 2017; 
Du et al. 2019). The government could realize the emission reduction target by deploying clean energy technologies and encouraging investments in low-carbon projects (Jordaan et al. 2017). Considering patent data provide a number of valuable information on the patent's technological content and citations, patents are still the most commonly used proxy for studying innovation activities in the scientific literature (Park 2014; Albino et al. 2014). Besides, combined Patent Classification (CPC), jointly promulgated by the European Patent Office and the United States Patent Office, has become one of the most popular patent classification systems since 2013 (Wang et al. 2020). The Y02 section in the CPC system includes patents for technologies or applications that mitigate or adapt to climate change. Thus, here we use the number of CPC-Y02 patent applications to represent low-carbon innovation in different Chinese provinces; then, we collect the data of patent applications from the IncoPat database ${ }^{4}$. To avoid heteroscedasticity and consider the low amount of lowcarbon innovation applications in some regions, this study takes the logarithm of the number of patent applications plus one as the proxy variable.

\section{Data sources}

We collect data from many official sources. Such as the China Statistical Yearbook(2001-2019), the China Energy Statistical Yearbook(2001-2018), the China Environmental Statistics Yearbook, the Statistical Yearbook of each province(2001-2018), and the National Bureau of Statistics official website database(2001-2018). The number of patent applications was obtained from the Incopat patent search platform, and the search scope is in the low-carbon field applied for in the China Patent Office (SIPO) from 2000 to 2017. Based on data availability, this paper excludes Hong Kong, Macao, Taiwan, and Tibet due to its data are missing. In summary, the data sample comprises panel data from 30 provinces and 18 years, which produces a balanced panel with 540 observations.

\section{Spatio-temporal evolution characteristics of carbon reduction potential}

\section{Temporal characteristics of carbon reduction potential}

\section{Time series characteristics of carbon reduction potential}

This paper conducts a temporal analysis of data to explore the Spatio-temporal differences and changes of CRP. We use MATLAB software to classify and summarize the CRP and ranking of various provinces in China. We select 2001, 2006, 2011, and 2017 as typical years. In addition, the Chinese mainland is divided into three groups (eastern, central, and western) to analyze the regional variations of average CRP under moderation (Table 4), fairness (Table 5), and efficiency (Table 6) scenarios.

There are differences in the CRP among different provinces/regions under three different scenarios. (i) Moderation scenario. The average MCRP in all regions decreased from 0.334 in 2001 to 0.312 in 2017, decreased significantly from 2006 to 2008, but volatility increased between 2008 and 2017. In terms of subregions, the MCRP in the three regions has been increasing first and then gradually decreasing. The average MCRP in the eastern region is higher than that of the other two regions. The average growth rate of MCRP found the lowest in the eastern region, followed by the central and the western regions, with average annual growth rates of $0.10 \%, 1.40 \%$, and $1.80 \%$, respectively. In terms of provinces, the provinces Shanxi, Inner Mongolia, and Ningxia were ranked as the top three places for the average MCRP with values of $0.534,0.431,0.418$, respectively. However, the bottom three provinces for the average MCRP were Guangxi, Hainan, and Jiangxi, with values of $0.213,0.221$, and 0.222 , respectively.

(ii) Fairness scenario. The average FCRP in all regions increased from 0.251 in 2001 to 0.331 in 2017, decreased quickly from 2006 to 2008, and increased from 2008 to 2017. In terms of subregions, the FCRP in the three regions showed a fluctuating upward trend. The FCRP in the eastern region found the highest, followed by the central and the western regions. The eastern region had the fastest average growth rate of the three regions, with average annual growth rates of $2.09 \%, 0.69 \%$, and $0.52 \%$, respectively. In terms of provinces, the provinces Shanxi, Inner Mongolia, and

\footnotetext{
${ }^{4}$ http://www.incopat.com
} 
Shanghai were ranked as the top three places for the average FCRP with values of $0.471,0.404$, and 0.398 , respectively. However, the bottom three provinces for the average FCRP were Guangxi, Jiangxi, and Yunnan, with values of 0.167 , 0.175 , and 0.180 , respectively.

(iii) Efficiency scenario. The average ECRP in all regions decreased from 0.417 in 2001 to 0.296 in 2017 . In terms of subregions, the ECRP in the three regions showed a fluctuating downward trend. The ECRP in the eastern region showed relatively lower degrees from 2000 to 2006, while it increased sharply and became the highest after 2008. The average growth rate of ECRP found the highest in the eastern region, while the central and the western regions exhibited negative growth, with average annual growth rates of $1.58 \%,-2.94 \%$, and $-3.56 \%$, respectively. In terms of provinces, the provinces Shanxi, Ningxia, and Inner Mongolia were ranked as the top three places for the average ECRP with values of 0.598 , 0.466, and 0.459, respectively. However, the bottom three provinces for the average ECRP were Hainan, Guangxi, and Jiangxi, with values of $0.257,0.259$, and 0.268 , respectively.

Overall, the eastern region's economy is more developed, and its average CRP is obviously higher than that of the other two regions, indicating that there is still a lot of space for reducing carbon emissions in the eastern region; meanwhile, the relatively underdeveloped economy makes carbon reduction potential very low in most provinces in the central and western regions. In terms of provinces, the above analysis demonstrates that the top two provinces for the average CRP are Shanxi and Inner Mongolia; while Guangxi and Jiangxi have been the bottom two provinces in China, indicating that the CRP shows a slight polarization in the central and western regions, the polarization may result from various factors such as the level of economic development, the proportion of heavy industries, the consumption of high-carbon energy, and production technology. Hence, it is necessary to research how to enhance carbon reduction capacity effectively in most provinces and make more room for carbon emission reduction.

\section{Dynamic evolution analysis of carbon reduction potential}

The dynamic evolution analysis results provide information for the current distributions of CRP and the variation in the provincial gap. Thus, we employ KDE to reveal the dynamic evolution of provincial CRP for 2001、2006、2008、2011, and 2017. Fig.1-3 show the Kernel density estimations, drawn by Stata 15.0, for MCRP, FCRP, and ECRP, respectively.

According to Fig. 1-3, the following features are evident by comparing the dynamic evolution of the MCRP, FCRP, and ECRP. Firstly, see from the trend of the KDE curve, the curves and their centers of three scenarios moved slightly to the right from 2001 to 2006, and then moved to the left after 2006, suggesting that the CRP gradually increased first and then gradually decreased during the study period. Secondly, see from the kurtosis of the KDE curve, the peaks and ranges of three different scenario curves experienced varying degrees of change. The modes where the MCRP and ECRP were low evolved from a wide to sharp one from 2001 to 2006, with the height ascending, revealing that the regional gap of MCRP and ECRP was shrinking at this stage. Furthermore, the dispersion range slightly widened after 2006, with the height descending, indicating that the gap among CRPs of different provinces was enlarging. Thirdly, see from the shapes of the KDE curve, the curves of fairness and efficiency scenario for 2001, 2006, and 2008 were bi-modal and showed a rise at the right end, while those for 2011 and 2017 were unimodal. Besides, the curve of the moderation scenario was unimodal, and with several lumps in the long right tail, which means that the CRP shows slight polarization.

Overall, provincial CRPs in China were enhancing from 2001 to 2008, with the provincial gap of MCRP and ECRP enlarged from 2001 to 2008 and bi-polarization tendency was weakened during 2011 and 2017. The peak of the curve in 2017 was the lowest and smoothest, which means that inter-provincial CRP level disparity in China was the narrowest in 2017.

\section{Spatial characteristics of carbon reduction potential}

\section{Global Spatial autocorrelation}

This study tests the spatial correlation of MCRP, FCRP, and ECRP from 2000 to 2017. Table 7 presents the results of global Moran index, the global Moran indices of CRP are positive at least at the 5\% level of significance, indicating a significant positive spatial autocorrelation among the 30 provinces over time. The spatial dependence of MCRP, FCRP, 
and ECRP has shown a significant growth trend since 2000, but after 2011, the Moran's I index began to decline fluctuant, indicating that the spatial autocorrelation of regional CRP has weakened after 2011. Moreover, the spatial correlations in 2009, 2010, and 2011 were relatively large, which indicates that the spatial dependence of CRP has an inverted "U" pattern, which first increases and then weakens.

Specifically, (i) The global Moran's I index of MCRP increased from 0.136 in 2000 to 0.296 in 2010, and then showed a downward trend, which proves that strong geographic dependence and spatial autocorrelation in provincial CRP. (ii) The global Moran's I index of FCRP had been fluctuant increasing from 2000 to 2009, and then showed a fluctuant downward trend after 2009. (iii) The global Moran's I index of ECRP increased fluctuant from 0.135 in 2000 to 0.278 in 2011, and then showed a fluctuant downward trend.

\section{Local spatial autocorrelation}

To reveal the spatial local auto-correlation and distribution pattern of China's provincial CRP, we draw Moran scatter plots for only 2009 and 2017 owing to the limited space available (see Fig. 4 to 6). The first and the third quadrant, with $\mathrm{H}-\mathrm{H}$ type provinces and L-L type provinces, respectively, indicate the province with high/low CRP is surrounded by provinces with high/low CRP, while the second and the fourth quadrant, with L-H type provinces and H-L type provinces, respectively, show the polarization characteristics.

It can be seen from the figure that most provinces with high CRP are located mainly in the eastern and central region (quadrant I) under three scenarios, such as Shanxi, Tianjin, Liaoning and other provinces. These provinces poss abundant natural resources and increasingly close regional cooperation mechanisms, all of which have a positive effect on the surrounding province (Chen et al. 2020). Clusters provinces with low CRP are concentrated in the western region (quadrant III), including Guansu, Yunnan, and other provinces, as may result from most provinces in the western region have underdeveloped economies and lower emissions efficiency. L-H type was mainly distributed in Anhui, Jilin, and Henan. For these provinces, technical exchanges and cooperation with neighboring provinces could be strengthened to improve CRP. H-L type was prevalent in Guangdong and Jiangsu. These provinces are relatively rich in economy and energy technology, so that they could help their neighboring areas to increase carbon reduction capability through regional cooperation.

Specifically, (i)The sum of H-H type and L-L type provinces account for $73.3 \%$ (22 provinces) of the provinces in 2017, up from 63.3\% (19 provinces) in 2009, which means that the spatial clustering is increasing, and the spatial polarization feature of provinces' MCRP appeared. For instance, Shanghai transformed from H-L type in 2009 to H-H type in 2017, as may result from Shanghai have a positive radiative effect and its neighboring developing new sustainable clean technologies to increase CRP. (ii) The sum of H-H type and L-L type provinces account for $60 \%$ (18 provinces) of the provinces in 2017, down from 70\% (21 provinces) in 2009, which means that the spatial clustering of provinces' FCRP is decreasing, and the spatial polarization feature weakened. (iii) The sum of H-H type and L-L type provinces account for $73.3 \%$ (22 provinces) of the provinces in 2017, down from $76.6 \%$ (23 provinces) in 2009 , indicating that the spatial clustering of provinces' FCRP is increasing slightly.

\section{Empirical results}

\section{Model selection}

Before conducting spatial analysis, the first step is to focus attention on the selection of spatial econometric models. Firstly, we employed the LM test to examine whether a spatially lagged dependent variable (LM spatial lag) or a spatially autocorrelated error term (LM spatial error) should be included in the model. According to the LM test results (Table 8), the LM-lag and LM-error test statistics are significant at the $1 \%$ level of significance, which indicates that the spatial model is a more appropriate specification than the non-spatial model. Then, the robust LM-lag and the robust LM-error statistic are significant, with a significance level of at least $1 \%$, indicating that the factors affecting CRP include not only independent variables and their lag terms but also some unobservable error terms. Secondly, this paper conducted the 
likelihood ratio ( LR ) test to test further the existence of spatial effects. According to Table 8, the LR test results show that the SDM is estimated as this study preferred specification. Finally, it essential to judge whether the correct panel data specification is a random effect or a fixed effect model through the Hausman test. The Hausman test statistics is significant at the $1 \%$ level of significance, which indicates that this paper should use the SDM of fixed effect (Table 8).

\section{$391 \quad$ Results of spatial Durbin estimation}

For a spatial econometric model, the estimated coefficients of independent variables are not of great significance. What really needs to be explained are the direct effects, indirect effects of independent variables in space. As the estimation coefficients of explanatory variables do not represent the marginal effects of the independent variables on the dependent variable, we estimate the direct and indirect effects of independent variables on the dependent variable following LeSage and Pace (2009). Table 9 reports on the results of the estimated coefficients of the influencing factors affecting CRP under various scenarios, in which columns (1)-(3), columns (4)-(6), columns (7)-(9) represent the result under moderation, fairness, and efficiency scenario, respectively.

According to Table 9, the regression coefficients of GDP on MCRP, FCRP, and ECRP are positive at the 1\% level of significance, W_GDP has a negative and significant effect. The direct effects of GDP are significantly positive, and the indirect effects of GDP are significantly negative, which indicates that economic development has significant spatial spillover effects. Improving regional economic development in local provinces can significantly increase local CRP, but it may inhibit neighboring provinces' CRP, which may result from economic growth promotes the local accumulation of various resource, and then siphon effect has caused the neighboring province to face the pressure of losing resources and innovative elements, leading to the potential space for carbon emission reduction has been compressed. Thus, economic development is the main factor for enhancing the local CRP.

The regression coefficient of IND is negative at the $1 \%$ level of significance, and the direct and indirect effects of IND on MCRP, FCRP, and ECRP are negative and significant. We can conclude that adjusting the industrial structure in local provinces can increase local and neighboring provinces' carbon reduction potential. Most Chinese provinces' development mode is relatively rough and their industrial structure is relatively backward for a long time. Furthermore, many scholars established that the secondary industry is the leading producer of carbon emissions (Cole et al. 2008; Cheng et al. 2018). Due to many companies in the secondary industry are generally characterized by high energy consumption and high carbon-emitting, improvement of industrial structure facilitates the flow of various factors from low-efficiency sectors to high-efficiency sectors (Zhou et al. 2013), which additionally increasing the potential of carbon emission reduction. Therefore, industrial structure optimization is an effective way to improve provincial carbon emission reduction potential and reduce regional carbon emissions.

From the spillover effect decomposition analysis, GREEN has a negative effect on FCRP in local provinces, while GREEN has a positive effect on ECRP in local and neighboring provinces. These results indicate that improving lowcarbon technologies can contribute to the local carbon emission reduction and provide critical support for local CRP under the efficiency scenario; in contrast, enhancing low-carbon innovation capability could restrain the local CRP under the fairness scenario. Low-carbon innovation can bring about an improvement in energy factor utilization and rapid development in new products. Especially in the process of increasing CRP by low-carbon technological progress, it is the efficiency-driven policy that plays the primary role. Therefore, we conclude that low-carbon innovation is a critical path that the province uses to increasing local CRP and promoting low-carbon transformation in the adjacent provinces from the perspective of efficiency.

The regression coefficient of ES is positive at the 1\% level of significance, and direct effect coefficients of ES on MCRP, FCRP, and ECRP are positive at the $1 \%$ level of significance, indicating that energy structure optimization has significant spatial spillover effects. However, only under the efficiency scenario, the indirect effect coefficient is 0.197 , which is not significant, suggesting that adjustment of energy structure in local provinces has only marginally contributed to adjacent provinces' ECRP. The energy consumption structure in China is dominated by coal (Lin and Wang 2020), coal consumption is the major source of greenhouse gas emissions and environmental problems (Wang et al. 2012). The higher 
consumption of the province will provide more room for carbon emission reduction. Hence, switching to renewable energy and improving the coal-based energy structure would provide essential support for local carbon emission reduction.

According to Table 9, it can be seen that the increase in energy efficiency will significantly increase ( $1 \%$ significance level) local CRP under three scenarios, while only under the fairness scenario, the indirect effect coefficient is 0.009 , which is not significant. The results show that energy efficiency has a significantly positive impact on the surrounding areas' CRP except for the fairness scenario. The main reason is that the improvement of energy efficiency brings effective energy utilization (Jin et al. 2017). Due to the demonstration effect on neighboring areas, provinces with low energy efficiency usually strive to bring in technology promotion strategies, practical experiences of local policies of Provinces with high efficiency (Song et al. 2018). Therefore, energy efficiency can be regarded as the vital factor of enhancing carbon reduction potential.

The direct effects of OPEN and POP on MCRP, FCRP, and ECRP were not significant, the indirect effects of POP are significantly positive under three scenarios, indicating that openness can not significantly increase CRP, especially the openness that deviates from the green development orientation is not conducive to regional emission reduction. Moreover, the effect of population size on CRP is not limited to local provinces, and can enhance carbon reduction potential across provinces through population movement.

\section{Conclusions and policy implications}

\section{Conclusions}

This study evaluates the carbon shadow price and the CRP index under the three scenarios of moderation, fairness, and efficiency. Based on the evaluation data, we analyze the spatial-temporal patterns and dynamic evolution of provincial CRP from 2001-2017 in China. Then, we employ exploratory spatial data analysis and SDM to explore the influence factors of CRP under three different scenarios. The main conclusions are as follows:

First, there are differences between different provinces/regions' CRP under three different scenarios from 2000 to 2017 the average MCRP and average ECRP showed a gradual downward trend, while the average FCRP showed an upward volatility trend. There also have substantial differences between the regions. MCRP and FCRP in the eastern region were found the highest, whereas ECRP in the eastern region was the highest after 2008. Further, there exists a slight polarization in the central and western regions.

Second, the spatial autocorrelation test indicated that the provinces with a similar CRP showed a significant geographic agglomeration, and the agglomeration effect was strengthened first and then weakened over time. Besides, most provinces with high CRP are located mainly in the eastern and central regions, such as Shanxi, InnerMongolia. These provinces poss abundant natural resources and have a positive effect on the surrounding province. Clusters provinces with low CRP are concentrated in the western region. These provinces have underdeveloped economies.

Lastly, through the SDM analysis and spillover effect decomposition, we conclude that improvements in regional CRP not only depend on economic development, industrial structure adjustment, and energy efficiency elevation, but also involve energy structure optimization, low-carbon innovation and population. It is noteworthy that there are differences in the effects of low-carbon innovation under different scenarios. The low-carbon innovation provides critical support for local CRP under the efficiency scenario but restrains the local CRP under the fairness scenario.

\section{Policy implications}

Based on the above conclusions, the policy implications for regional carbon reduction potential improvement are as follows.

Firstly, The central government should fully consider the heterogeneity of factors such as economic development, resource conditions, and carbon emission potentials in various regions when formulating carbon reduction policies. The government must emphasize local conditions and make the ex-ante scenario assessment, pay more attention to areas with 
high CRPs and appropriately control areas with low CRPs. For example, such as the leading coal production provinces with low marginal abatement costs, Shanxi and Inner Mongolia etc., should assume higher carbon reduction targets to unlock the carbon reduction potential. While underdeveloped provinces with slow energy structure adjustments, such as Hainan and Qinghai, should assume looser carbon reduction constraints. Overall, the government should guide innovation and human resources flow to the central and western regions and high-carbon areas with high emission reduction potential to improve emission reduction efficiency while reducing total social costs.

Secondly, emphasize the cross-regional collaboration of carbon emission control. The "spillover" of social capital, talents, low-carbon technology make it easy to achieve the goal of inter-regional coordinated development of carbon reduction. To break the current situation of low carbon reduction potential among the western regions, carbon reduction strategies should be established based on "joint prevention and control". Specifically, for H-L agglomeration areas, strengthening the leading role in developed economic areas, such as Guangdong and Jiangsu, and reinforcing the spillover of capital, environmental protection technologies, and other factors to enhance the radiation effect from the "center" to the "periphery". For low-low agglomeration areas with underdeveloped economies, such as Guangxi and Gansu, CRP could be enhanced by encouraging develop clean energy (e.g., photovoltaic, wind energy, tidal energy) and increasing special fund support and guarantee to weaken the siphon effect.

Thirdly, explore the carbon reduction paths characterized by sustainable and low-carbon development governed in multiple dimensions. The study shows that improvement in economic, industrial structure, and energy efficiency elevation will not only effectively enhance the local CRP but also have a significant spatial spillover effect. Therefore, it is essential to optimize energy efficiency and explore economic growth paths characterized by sustainable and low-carbon development. On the one hand, through tax incentives and low-interest loans, the government can encourage and support the local research institutes and enterprises in developed areas to carry out the production, transformation, and application of low-carbon innovation, which is an indispensable strategy for advancing energy efficiency. Meanwhile, the government could introduce voluntary energy efficiency standards for various sectors, especially high-carbon industries, to stimulate industrial energy efficiency improvements. On the other hand, the government could vigorously promote the application of clean energy in transport, industry, and construction through financial subsidies and pollution penalties to get rid of coal dependence gradually. Simultaneously, we should formulate relevant policies to guide enterprises to transition toward the tertiary industry to accelerate de-industrialization progress. In particular, the government should increase subsidies for outstanding talents and foster regional knowledge collaboration.

Authors' contributions All authors contributed to the study conception and design. Zhangwen Li acquired, analyzed, and interpreted the data, drafted the article or revised it critically for important intellectual content, and was a major contributor in writing the manuscript. Caijiang Zhang revised it critically for intellectual content and approved the version to be published. Yu Zhou acquired the data and made substantial contributions to the conception or design of the work. All authors read and approved the final manuscript.

508 Funding No funding was received for conducting this study.

Data availability The datasets used and analyzed during the current study are available from the corresponding author on reasonable request.

\section{Compliance with ethical standards}

512 Competing interests The authors declared that they have no conflict of interest.

513 Ethics approval and consent to participate Not applicable

514 Consent for publication All authors have read and approved the final manuscript. 


\section{References}

Aigner DJ, Chu SF (1968) On estimating the industry production function. Am Econ Rev 58:826-839

Akimoto K, Sano F, Homma T, et al (2010) Estimates of GHG emission reduction potential by country, sector, and cost. Energy Policy 38:3384-3393. https://doi.org/10.1016/j.enpol.2010.02.012

Albino V, Ardito L, Dangelico RM, Messeni Petruzzelli A (2014) Understanding the development trends of low-carbon energy technologies: A patent analysis. Appl Energy 135:836-854. https://doi.org/10.1016/j.apenergy.2014.08.012

An R, Yu B, Li R, Wei Y-M (2018) Potential of energy savings and $\mathrm{CO}_{2}$ emission reduction in China's iron and steel industry. Appl Energy 226:862-880. https://doi.org/10.1016/j.apenergy.2018.06.044

Anselin L (1995) Local Indicators of Spatial Association-LISA. Geogr Anal 27:93-115. https://doi.org/10.1111/j.15384632.1995.tb00338.x

Bian Y, He P, Xu H (2013) Estimation of potential energy saving and carbon dioxide emission reduction in China based on an extended non-radial DEA approach. Energy Policy 63:962-971. https://doi.org/10.1016/j.enpol.2013.08.051

Chen J, Cheng S, Song M, Wu Y (2016) A carbon emissions reduction index: Integrating the volume and allocation of regional emissions. Appl Energy 184:1154-1164. https://doi.org/10.1016/j.apenergy.2016.03.032

Chen J, Xiang D (2019) Carbon efficiency and carbon abatement costs of coal-fired power enterprises: A case of Shanghai, China. J Clean Prod 206:452-459. https://doi.org/10.1016/j.jclepro.2018.09.087

Chen J, Xu C, Cui L, et al (2019) Driving factors of $\mathrm{CO}_{2}$ emissions and inequality characteristics in China: A combined decomposition approach. Energy Econ 78:589-597. https://doi.org/10.1016/j.eneco.2018.12.011

Chen Y, Zhu B, Sun X, Xu G (2020) Industrial environmental efficiency and its influencing factors in China: analysis based on the Super-SBM model and spatial panel data. Environ Sci Pollut Res 27:44267-44278. https://doi.org/10.1007/s11356-02010235-y

Cheng M, Shao Z, Gao F, et al (2020) The effect of research and development on the energy conservation potential of China's manufacturing industry: The case of east region. J Clean Prod 258:120558. https://doi.org/10.1016/j.jclepro.2020.120558

Cheng Z, Li L, Liu J (2018) Industrial structure, technical progress and carbon intensity in China's provinces. Renew Sustain Energy Rev 81:2935-2946. https://doi.org/10.1016/j.rser.2017.06.103

Choi Y, Zhang N, Zhou P (2012) Efficiency and abatement costs of energy-related $\mathrm{CO}_{2}$ emissions in China: A slacks-based efficiency measure. Appl Energy 98:198-208. https://doi.org/10.1016/j.apenergy.2012.03.024

Chung YH, Färe R, Grosskopf S (1997) Productivity and undesirable outputs: a directional distance function approach. J Environ Manage 51:229-240. https://doi.org/10.1006/jema.1997.0146

Cole MA, Elliott RJR, Wu S (2008) Industrial activity and the environment in China: an industry-level analysis. China Econ Rev 19:393-408. https://doi.org/10.1016/j.chieco.2007.10.003

Criqui P, Mima S, Viguier L (1999) Marginal abatement costs of $\mathrm{CO}_{2}$ emission reductions, geographical flexibility and concrete ceilings: an assessment using the POLES model. Energy Policy 27:585-601. https://doi.org/10.1016/S0301-4215(99)00051-8

den Elzen MGJ, Lucas PL (2005) The FAIR model: A tool to analyse environmental and costs implications of regimes of future commitments. Environ Model Assess 10:115-134. https://doi.org/10.1007/s10666-005-4647-z

Dietz T, Rosa EA (1994) Rethinking the environmental impacts of population, affluence and technology. Hum Ecol Rev 1:277-300

Ding L, Yang Y, Wang W, Calin AC (2019) Regional carbon emission efficiency and its dynamic evolution in China: A novel cross efficiency-malmquist productivity index. J Clean Prod 241:118260. https://doi.org/10.1016/j.jclepro.2019.118260

Dong F, Long R, Yu B, et al (2018) How can China allocate $\mathrm{CO}_{2}$ reduction targets at the provincial level considering both equity and efficiency? Evidence from its Copenhagen Accord pledge. Resour Conserv Recycl 130:31-43. https://doi.org/10.1016/j.resconrec.2017.11.011

Du K, Li P, Yan Z (2019) Do green technology innovations contribute to carbon dioxide emission reduction? Empirical evidence from patent data. Technol Forecast Soc Change 146:297-303. https://doi.org/10.1016/j.techfore.2019.06.010

Färe R, Grosskopf S, Lovell CAK, Yaisawarng S (1993) Derivation of shadow prices for undesirable outputs: a distance function 
approach. Rev Econ Stat 75:374-380. https://doi.org/10.2307/2109448

Färe R, Grosskopf S, Noh D-W, Weber W (2005) Characteristics of a polluting technology: theory and practice. J Econom 126:469492. https://doi.org/10.1016/j.jeconom.2004.05.010

Färe R, Grosskopf S, Weber WL (2006) Shadow prices and pollution costs in U.S. agriculture. Ecol Econ 56:89-103. https://doi.org/10.1016/j.ecolecon.2004.12.022

Geng Y, Zhao H, Liu Z, et al (2013) Exploring driving factors of energy-related $\mathrm{CO}_{2}$ emissions in Chinese provinces: A case of Liaoning Energy Policy 60:820-826. https://doi.org/10.1016/j.enpol.2013.05.054

Guo X-D, Zhu L, Fan Y, Xie B-C (2011) Evaluation of potential reductions in carbon emissions in Chinese provinces based on environmental DEA. Energy Policy 39:2352-2360. https://doi.org/10.1016/j.enpol.2011.01.055

IPCC (2006) IPCC Guidelines for National Greenhouse Gas Inventories. https://www.ipcc-nggip.iges.or.jp/public/2006gl/index.html. Accessed 5 Mar 2021

Ji DJ, Zhou P (2020) Marginal abatement cost, air pollution and economic growth: Evidence from Chinese cities. Energy Econ 86:104658. https://doi.org/10.1016/j.eneco.2019.104658

Jiang J, Ye B, Xie D, Tang J (2017) Provincial-level carbon emission drivers and emission reduction strategies in China: Combining multi-layer LMDI decomposition with hierarchical clustering. J Clean Prod 169:178-190. https://doi.org/10.1016/j.jclepro.2017.03.189

Jin L, Duan K, Shi C, Ju X (2017) The impact of technological progress in the energy sector on carbon emissions: an empirical analysis from China. Int J Environ Res Public Health 14:1505. https://doi.org/10.3390/ijerph14121505

Jordaan SM, Romo-Rabago E, McLeary R, et al (2017) The role of energy technology innovation in reducing greenhouse gas emissions: A case study of Canada. Renew Sustain Energy Rev 78:1397-1409. https://doi.org/10.1016/j.rser.2017.05.162

Ke T-Y, Hu J-L, Li Y, Chiu Y-H (2008) Shadow prices of $\mathrm{SO}_{2}$ abatements for regions in China. Social Science Research Network, Rochester, NY

Ketelaer T, Kaschub T, Jochem P, Fichtner W (2014) The potential of carbon dioxide emission reductions in German commercial transport by electric vehicles. Int J Environ Sci Technol 11:2169-2184. https://doi.org/10.1007/s13762-014-0631-y

Lee J-D, Park J-B, Kim T-Y (2002) Estimation of the shadow prices of pollutants with production/environment inefficiency taken into account: a nonparametric directional distance function approach. J Environ Manage 64:365-375. https://doi.org/10.1006/jema.2001.0480

Lee M (2011) Potential cost savings from internal/external $\mathrm{CO}_{2}$ emissions trading in the Korean electric power industry. Energy Policy 39:6162-6167. https://doi.org/10.1016/j.enpol.2011.07.016

LeSage JP, Pace RK (2009) Introduction to spatial econometrics. CRC press, Boca Raton

Lin B, Ouyang X (2014) Analysis of energy-related $\mathrm{CO}_{2}$ (carbon dioxide) emissions and reduction potential in the Chinese non-metallic mineral products industry. Energy 68:688-697. https://doi.org/10.1016/j.energy.2014.01.069

Lin B, Wang Y (2020) Does energy poverty really exist in China? From the perspective of residential electricity consumption. Energy Policy 143:111557. https://doi.org/10.1016/j.enpol.2020.111557

Lin B, Xie C (2014) Reduction potential of $\mathrm{CO}_{2}$ emissions in China's transport industry. Renew Sustain Energy Rev 33:689-700. https://doi.org/10.1016/j.rser.2014.02.017

Liu Z, Guan D, Wei W, et al (2015) Reduced carbon emission estimates from fossil fuel combustion and cement production in China. Nature 524:335-338. https://doi.org/10.1038/nature14677

Ma G, Li X, Zheng J (2020) Efficiency and equity in regional coal de-capacity allocation in China: A multiple objective programming model based on Gini coefficient and Data Envelopment Analysis. Resour Policy 66:101621. https://doi.org/10.1016/j.resourpol.2020.101621

Molinos-Senante M, Hanley N, Sala-Garrido R (2015) Measuring the $\mathrm{CO}_{2}$ shadow price for wastewater treatment: A directional distance function approach. Appl Energy 144:241-249. https://doi.org/10.1016/j.apenergy.2015.02.034

Pan X, Elzen M den, Höhne N, et al (2017) Exploring fair and ambitious mitigation contributions under the Paris Agreement goals. Environ Sci Policy 74:49-56. https://doi.org/10.1016/j.envsci.2017.04.020 
Park JY (2014) The evolution of waste into a resource: Examining innovation in technologies reusing coal combustion by-products using patent data. Res Policy 43:1816-1826. https://doi.org/10.1016/j.respol.2014.06.002

Qin Q, Liu Y, Li X, Li H (2017) A multi-criteria decision analysis model for carbon emission quota allocation in China's east coastal areas: Efficiency and equity. J Clean Prod 168:410-419. https://doi.org/10.1016/j.jclepro.2017.08.220

Shahbaz M, Loganathan N, Muzaffar AT, et al (2016) How urbanization affects $\mathrm{CO}_{2}$ emissions in Malaysia? The application of STIRPAT model. Renew Sustain Energy Rev 57:83-93. https://doi.org/10.1016/j.rser.2015.12.096

Shephard RW (1970) Theory of cost and production functions Princeton University press. Princeton University press

Shi Y, Sasai T, Yamaguchi Y (2014) Spatio-temporal evaluation of carbon emissions from biomass burning in Southeast Asia during the period 2001-2010. Ecol Model 272:98-115. https://doi.org/10.1016/j.ecolmodel.2013.09.021

Song M, Chen Y, An Q (2018) Spatial econometric analysis of factors influencing regional energy efficiency in China. Environ Sci Pollut Res 25:13745-13759. https://doi.org/10.1007/s11356-018-1574-5

Song Y, Huang J, Zhang Y, Wang Z (2019) Drivers of metal consumption in China: An input-output structural decomposition analysis. Resour Policy 63:101421. https://doi.org/10.1016/j.resourpol.2019.101421

Sun JW (2005) The decrease of $\mathrm{CO}_{2}$ emission intensity is decarbonization at national and global levels. Energy Policy 33:975-978. https://doi.org/10.1016/j.enpol.2003.10.023

Tang K, Gong C, Wang D (2016) Reduction potential, shadow prices, and pollution costs of agricultural pollutants in China. Sci Total Environ 541:42-50. https://doi.org/10.1016/j.scitotenv.2015.09.013

Tian X, Chang M, Tanikawa H, et al (2013) Structural decomposition analysis of the carbonization process in Beijing: A regional explanation of rapid increasing carbon dioxide emission in China. Energy Policy 53:279-286. https://doi.org/10.1016/j.enpol.2012.10.054

Wang K, Che L, Ma C, Wei Y-M (2017) The shadow price of $\mathrm{CO}_{2}$ emissions in China's iron and steel industry. Sci Total Environ 598:272-281. https://doi.org/10.1016/j.scitotenv.2017.04.089

Wang K, Wei Y-M, Zhang X (2012) A comparative analysis of China's regional energy and emission performance: Which is the better way to deal with undesirable outputs? Energy Policy 46:574-584. https://doi.org/10.1016/j.enpol.2012.04.038

Wang Q, Cui Q, Zhou D, Wang S (2011) Marginal abatement costs of carbon dioxide in China: A nonparametric analysis. Energy Procedia 5:2316-2320. https://doi.org/10.1016/j.egypro.2011.03.398

Wang W, Li Y, Lu N, et al (2020) Does increasing carbon emissions lead to accelerated eco-innovation? Empirical evidence from China. J Clean Prod 251:119690. https://doi.org/10.1016/j.jclepro.2019.119690

Wang Y, Zheng Y (2020) Spatial effects of carbon emission intensity and regional development in China. Environ Sci Pollut Res. https://doi.org/10.1007/s11356-020-11557-7

Wei C, Ni J, Du L (2012) Regional allocation of carbon dioxide abatement in China. China Econ Rev 23:552-565. https://doi.org/10.1016/j.chieco.2011.06.002

Wei W, Cai W, Guo Y, et al (2020) Decoupling relationship between energy consumption and economic growth in China's provinces from the perspective of resource security. Resour Policy 68:101693. https://doi.org/10.1016/j.resourpol.2020.101693

Yu S, Zheng S, Li X (2018) The achievement of the carbon emissions peak in China: The role of energy consumption structure optimization. Energy Econ 74:693-707. https://doi.org/10.1016/j.eneco.2018.07.017

Zhang L, Long R, Chen H (2019) Carbon emission reduction potential of urban rail transit in China based on electricity consumption structure. Resour Conserv Recycl 142:113-121. https://doi.org/10.1016/j.resconrec.2018.11.019

Zhang N, Wei X (2015) Dynamic total factor carbon emissions performance changes in the Chinese transportation industry. Appl Energy 146:409-420. https://doi.org/10.1016/j.apenergy.2015.01.072

Zhang Y, Wang W, Liang L, et al (2020) Spatial-temporal pattern evolution and driving factors of China's energy efficiency under lowcarbon economy. Sci Total Environ 739:140197. https://doi.org/10.1016/j.scitotenv.2020.140197

Zhang Y-J, Da Y-B (2015) The decomposition of energy-related carbon emission and its decoupling with economic growth in China. Renew Sustain Energy Rev 41:1255-1266. https://doi.org/10.1016/j.rser.2014.09.021

Zhang Y-J, Peng Y-L, Ma C-Q, Shen B (2017) Can environmental innovation facilitate carbon emissions reduction? Evidence from 
Zhou P, Zhou X, Fan LW (2014) On estimating shadow prices of undesirable outputs with efficiency models: A literature review. Appl Energy 130:799-806. https://doi.org/10.1016/j.apenergy.2014.02.049

Zhou X, Fan LW, Zhou P (2015) Marginal $\mathrm{CO}_{2}$ abatement costs: Findings from alternative shadow price estimates for Shanghai industrial sectors. Energy Policy 77:109-117. https://doi.org/10.1016/j.enpol.2014.12.009

Zhou X, Zhang J, Li J (2013) Industrial structural transformation and carbon dioxide emissions in China. Energy Policy 57:43-51. https://doi.org/10.1016/j.enpol.2012.07.017

Zhu Q, Li X, Li F, Zhou D (2020) The potential for energy saving and carbon emission reduction in China's regional industrial sectors. Sci Total Environ 716:135009. https://doi.org/10.1016/j.scitotenv.2019.135009

658 Publisher's Note Springer Nature remains neutral with regard to jurisdictional claims in published maps and institutional 659 affiliations. 
Figures

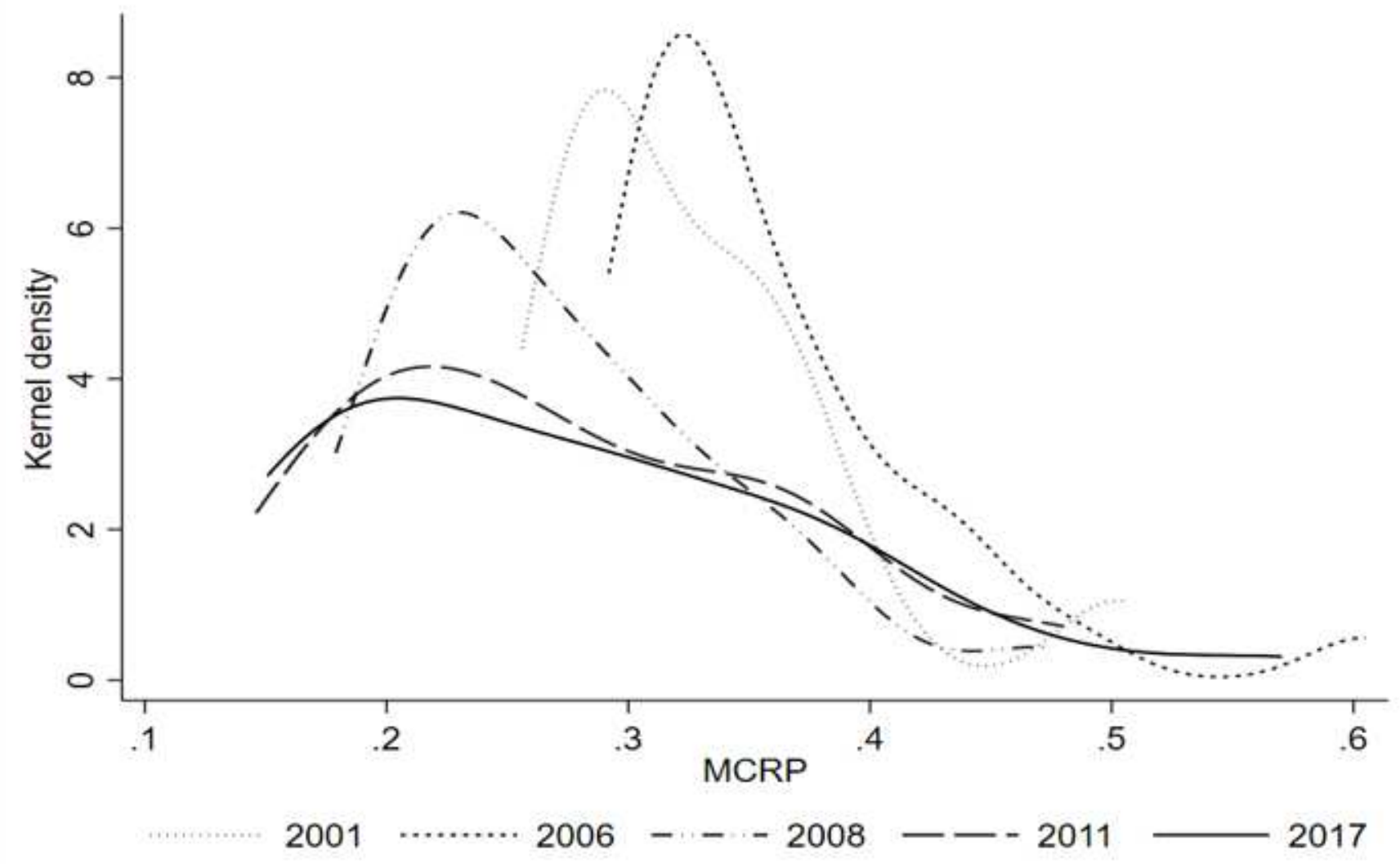

Figure 1

Kernel density plot of China's MCRP in selected years 


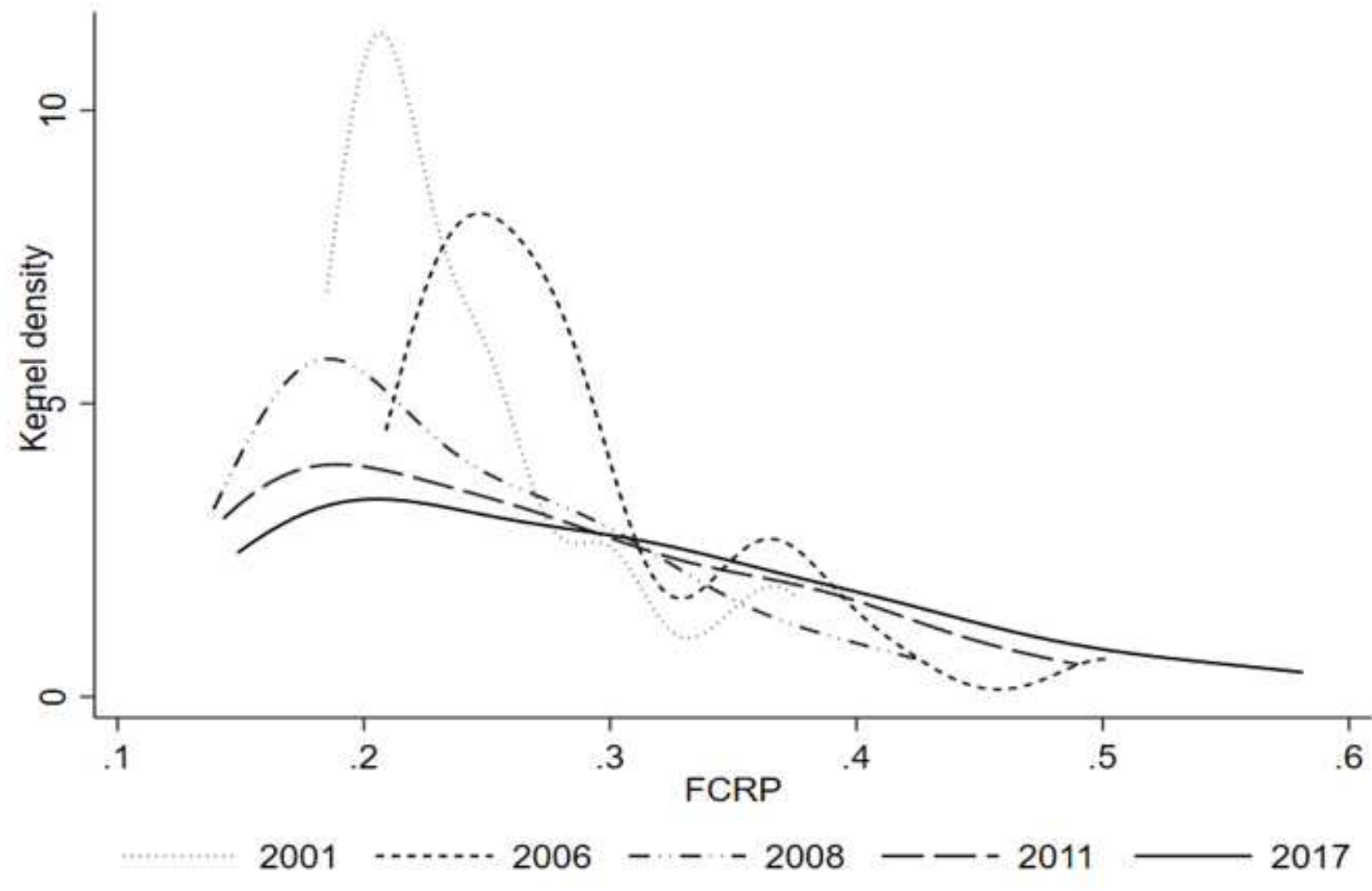

Figure 2

Kernel density plot of China's FCRP in selected years 


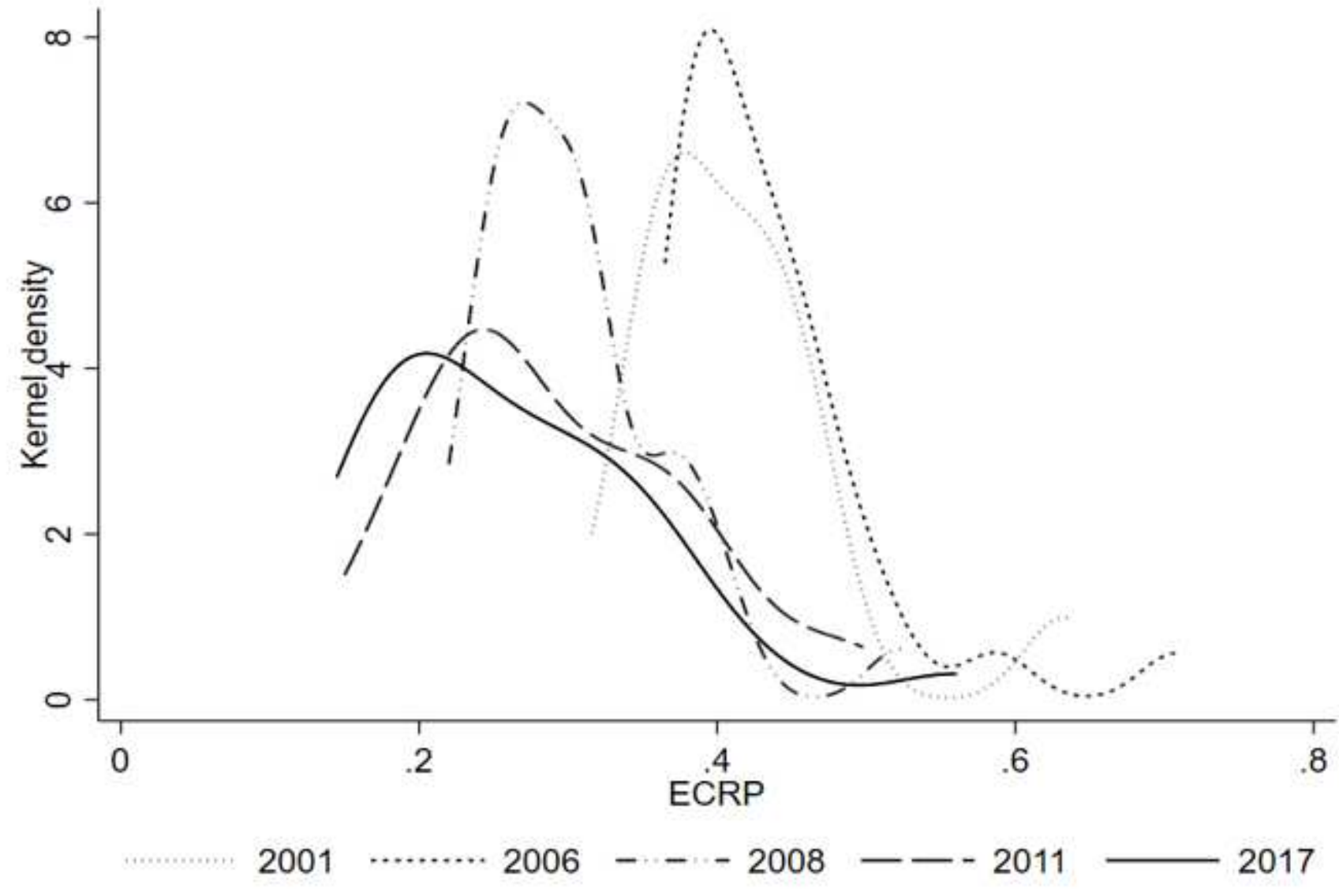

Figure 3

Kernel density plot of China's ECRP in selected years

a) Morans' $\mid=0.294$

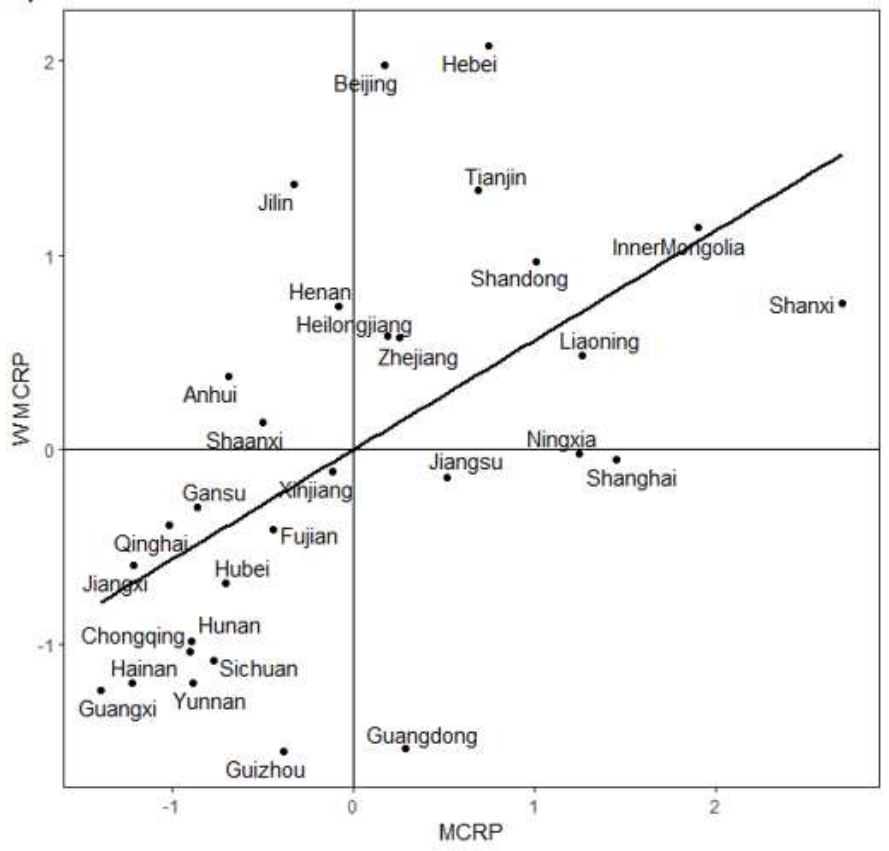

b) Morans' $=0.234$

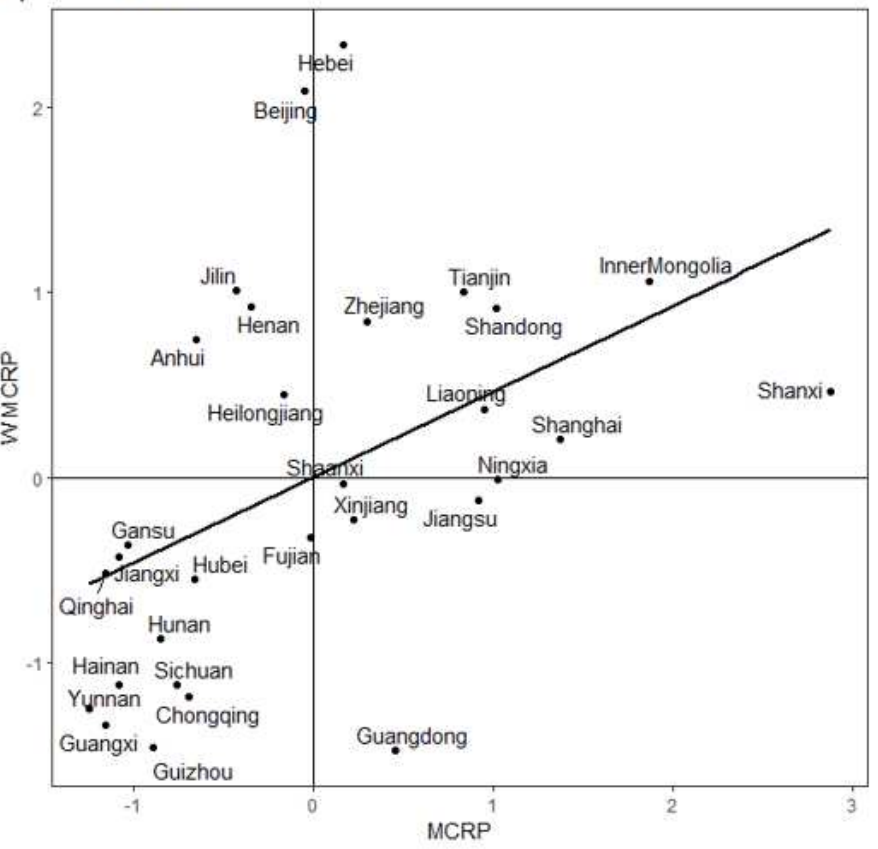


Figure 4

Moran scatter plots of MCRP in 2009 and 2017
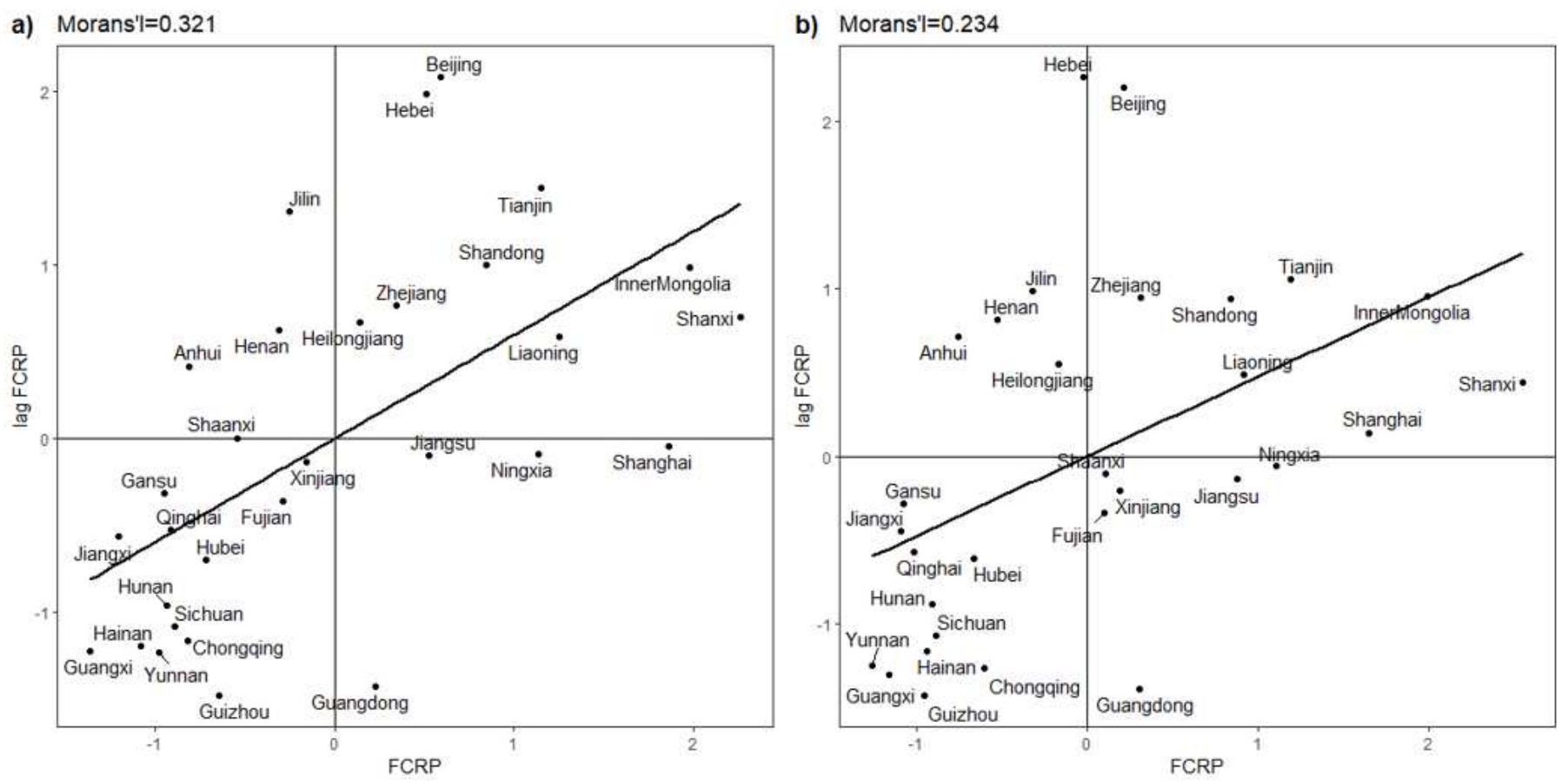

\section{Figure 5}

Moran scatter plots of FCRP in 2009 and 2017

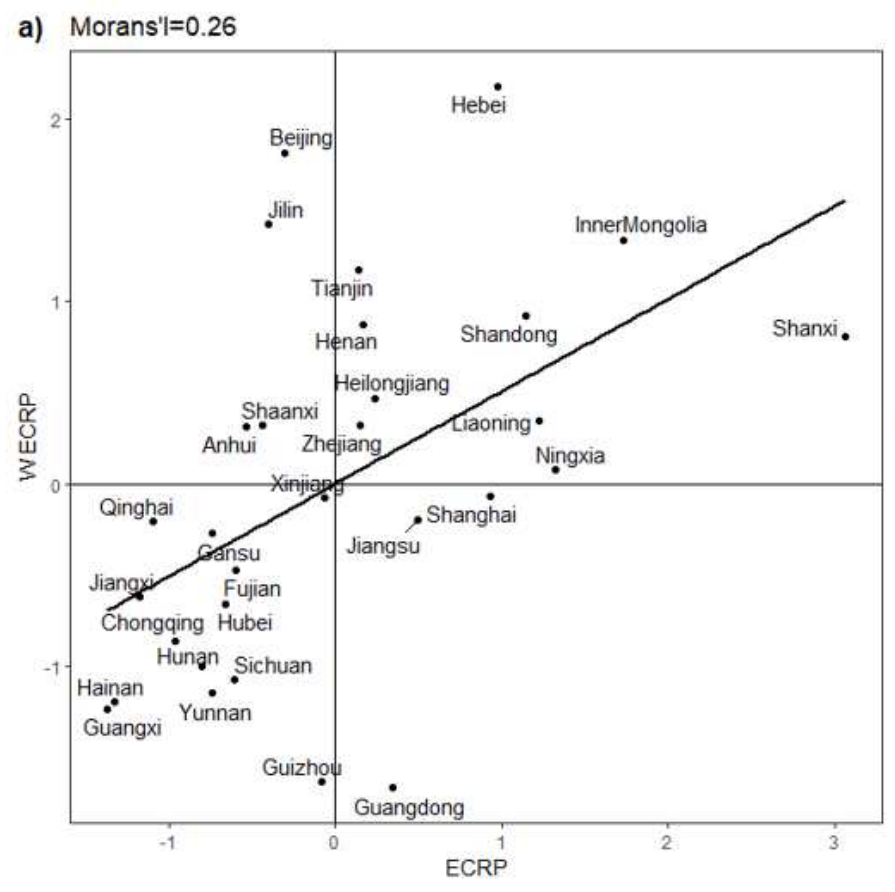

b) Morans' $1=0.222$

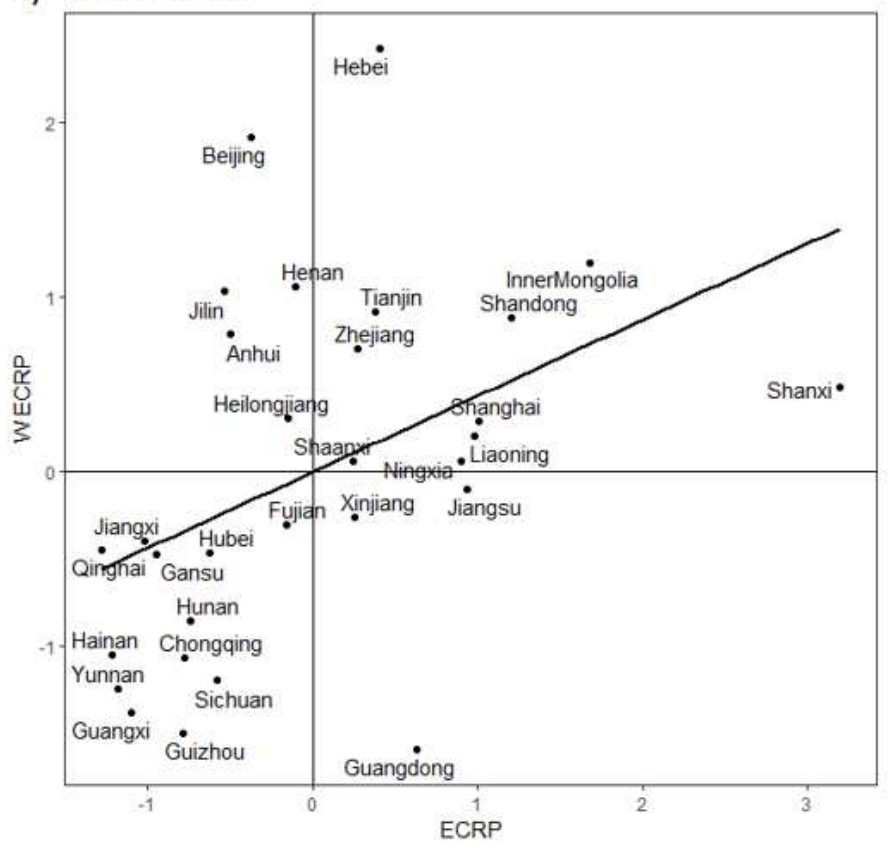

Figure 6

Moran scatter plots of ECRP in 2009 and 2017 


\section{Supplementary Files}

This is a list of supplementary files associated with this preprint. Click to download.

- Supplementarymaterial.pdf 